\title{
Kinetic Analysis of the Iron Oxide Reduction Using Hydrogen- Carbon Monoxide Mixtures as Reducing Agent
}

\author{
A. BONALDE, A. HENRIQUEZ and M. MANRIQUE' \\ Siderúrgica del Orinoco, SIDOR, Puerto Ordaz, Venezuela. \\ Caracas, Venezuela.
}

1) Materials Science Department, Universidad Simón Bolívar,

(Received on July 27, 2004; accepted on July 6, 2005)

\begin{abstract}
The kinetics of the reduction of hematite pellets using hydrogen-carbon monoxide mixtures as reducing agent was described by using the "grain model". This model involves the particle size and the porosity of the pellet as main structural parameters which affect directly the kinetics of the hematite pellets during the reduction process. The predictions of the model were compared with the experimental results. Fired hematite pellets were reduced at $850^{\circ} \mathrm{C}$ using hydrogen, carbon monoxide and Midrex gas. The weight loss technique was used to follow the reduction process. The reduction of iron oxide pellets using hydrogen or carbon monoxide is a mixed controlled system, where chemical reaction and internal gas diffusion are competing processes during the first stage of the reduction, while internal gas diffusion becomes controlling step at the last stage of the process. The reduction of iron oxide pellets using Midrex gas is a mixed controlled system throughout the whole reduction process.
\end{abstract}

KEY WORDS: iron oxide; direct reduction; kinetic model; Midrex gas.

\section{Introduction}

The technology of Direct Reduction Iron (DRI)Electric Arc Furnace for steelmaking is now one of the most important practices all over the world. Contributing factor in this industrial development are the advances in the Midrex and HyL direct reduction processes as well as the new electric arc furnace design and process control which place the sponge iron in better situation compared with scrap alternative. The high porosity, low density, low thermal conductivity, high surface area and intermediate carbon content leads DRI products to improve yield and productivity. The better knowledge of charge composition allows more accurate predictions of final composition and reduces the tap to tap time because of the continuous feeding.

While the reduction of iron oxides with $\mathrm{H}_{2}$ or $\mathrm{CO}$ has been extensively studied, the kinetics of the reduction with $\mathrm{H}_{2}-\mathrm{CO}$ mixtures is rather limited. The mathematical modeling for the reduction of iron oxide pellets is very important in understanding the kinetics of the reduction process which will help to define the operating parameters and to get a better control of the Midrex and HyL reactors. ElGeassy et al. ${ }^{1)}$ studied the mechanism of iron oxide reduction with $\mathrm{H}_{2}-\mathrm{CO}$ mixtures using pure iron oxide briquettes with different grain size, porosity and structure. They determined the activation energy for different gaseous mixtures. Haas et ll. $^{2)}$ investigated the use of $\mathrm{H}_{2}-\mathrm{H}_{2} \mathrm{O}-\mathrm{CH}_{4}-\mathrm{CO}-$ $\mathrm{CO}_{2}$ gas mixtures for reducing iron oxides. Their work showed that water vapor did not decrease the reduction rate rather than $\mathrm{CO}_{2}$. Also they observed carbon deposition at temperatures below $1000^{\circ} \mathrm{C}$ when reducing with $\mathrm{CO}-\mathrm{H}_{2}$ mixtures at low hydrogen concentrations. Towhidi and
Szekely ${ }^{3)}$ studied the influence of carbon deposition on the reduction kinetics of commercial grade hematite pellets with $\mathrm{CO}, \mathrm{H}_{2}$ and $\mathrm{N}_{2}$ mixtures. They found that carbon deposition occurred when operating at temperatures below $900^{\circ} \mathrm{C}$. At higher temperatures and high hydrogen content the carbon deposition decreased. The carbon deposited was primarily elemental carbon rather than cementite. Kang et $a l .{ }^{4)}$ used Ishida-Wen's mathematical model to describe the effect of the size and shape of the iron oxide samples during the reduction with $\mathrm{CO}-\mathrm{CO}_{2}$ mixtures at temperatures of 800 and $900^{\circ} \mathrm{C}$. Moon et al. ${ }^{5}$ studied the reduction behavior of hematite compacts by $\mathrm{H}_{2}-\mathrm{CO}$ gas mixtures at $800-950^{\circ} \mathrm{C}$. They observed that over the whole temperature range studied the reduction rate decreased with $\mathrm{CO}$ content in the gas mixture, the chemical reaction rate constant for $\mathrm{H}_{2}$ reduction was two to three times higher than that for $\mathrm{CO}$ reduction. They proposed that the reduction process was initially controlled by the chemical reaction at the oxide iron interface, mixed controlled in the intermediate reduction time and controlled by intraparticle diffusion towards the end of the reduction. Zhou et al. ${ }^{6)}$ used the JohnsonMehl-Avrami kinetic model to study the direct reduction of iron ore using $\mathrm{H}_{2}$. Rodriguez et al. ${ }^{7}$ studied the kinetics of hematite particles using $\mathrm{H}_{2}-\mathrm{CO}$ mixtures in the temperature range $550-650^{\circ} \mathrm{C}$. They found that the rate of reduction decreased as the concentration of $\mathrm{CO}$ increased in the gas mixture. Lin et al. ${ }^{8)}$ used the unimolecular model for $\mathrm{Fe}_{2} \mathrm{O}_{3}$ $\mathrm{Fe}_{3} \mathrm{O}_{4}$ reduction and a two-dimensional nucleation model according to Avrami-Erofeev for $\mathrm{Fe}_{3} \mathrm{O}_{4}-\mathrm{Fe}$ reduction stage using $\mathrm{H}_{2}$ as reducing agent. Ono-Nakazato et al. ${ }^{9)}$ used the Rist's model to study the effect of water-gas shift reaction on the reduction of iron oxide powder packed bed with $\mathrm{H}_{2}-$ 


\section{CO mixtures}

Increase of the capacity and productivity in the direct reduction reactor, improvement of the quality in the final product, decrease of gas consumption and reduction of gaseous emissions into the atmosphere strongly depend on design and operating parameters of the reactor. The purpose of this investigation is to study the kinetics of the reduction of a single iron oxide pellet using $\mathrm{H}_{2}-\mathrm{CO}$ mixtures and determine the rate controlling step of the reduction process by applying the "grain model" to analyze the experimental results. These results will be used in the first stage to study the kinetic behavior of the whole reduction reactor, in which more complex kinetic models are used to simulate the operation of the industrial reduction units.

\section{Mathematical Formulation}

The "grain model" initially proposed by Szekely and Evans ${ }^{10-12)}$ is used to describe the kinetics and mechanism of the iron oxide reduction by $\mathrm{H}_{2}, \mathrm{CO}$ and $\mathrm{H}_{2}-\mathrm{CO}$ mixtures. The system considered in the present work consists of a spherical pellet of radius $R_{\mathrm{o}}$ made of small grains with radius $r_{\mathrm{o}}$ and porosity $\varepsilon_{\mathrm{o}}$. The pellet is heated up to the reduction temperature in inert atmosphere and then brought into contact with $\mathrm{H}_{2}-\mathrm{CO}$ gas mixtures. In order to be able to formulate mathematical expressions describing the behavior of the system, the following tenable assumptions are made which do not cause major deviation from the actual situation:

(1) Isothermal process.

(2) Sintering and agglomeration in the pellet occurred during the reduction process is negligible.

(3) Hematite $\left(\mathrm{Fe}_{2} \mathrm{O}_{3}\right)$ is transformed to wustite $(\mathrm{FeO})$ very rapidly during the initial stage of the reduction process. This behavior has been observed previously in the reduction of porous iron oxide pellets. ${ }^{13}$ )

(4) The chemical reaction occurring at each grain proceeds in a topochemical fashion.

(5) A quasi-steady state approximation is assumed that the accumulation term in the diffusion equation is neglected.

(6) The effective diffusivity of gaseous reactants depends on Knudsen as well as molecular diffusion.

(7) Reversible, first-order chemical reaction with respect to the gaseous reactants is considered to take place at the reaction front within each grain. The mechanism of the reduction reactions is still not well understood, so this assumption will be the first approximation.

(8) The effect of bulk flow due to diffusion is considered to be negligible.

The problem is formulated by considering the general equation describing the diffusion of the gaseous reactants between the grains, and its consumption by the chemical reaction within the grains. A molar balance of gaseous reactant within the pellet yields the following dimensionless expressions:

$$
\frac{1}{\eta^{2}}\left(\frac{\partial^{2} C^{*}}{\partial \eta^{2}}+\frac{2}{\eta} \frac{\partial C^{*}}{\partial \eta}\right)-\left(1-\varepsilon_{\mathrm{o}}\right) \xi_{\mathrm{G}}^{2} \omega \lambda_{1} C^{*}=0 \ldots .
$$

where, $C^{*}=C_{\mathrm{i}} / C_{\mathrm{o}}$ : the dimensionless concentration of

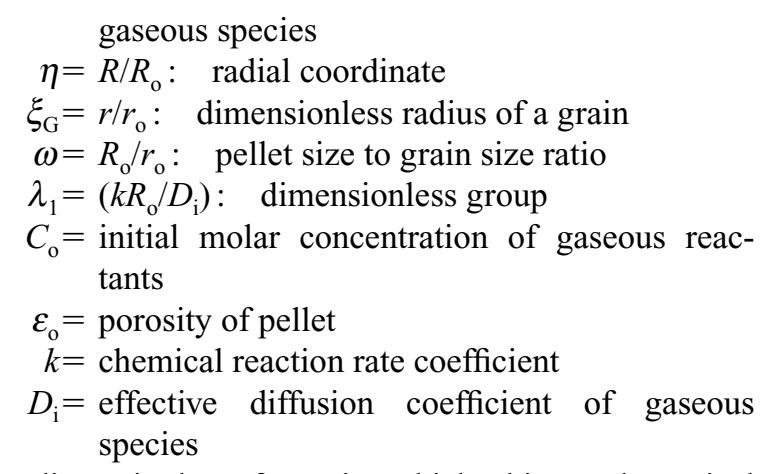

The dimensionless form in which this mathematical model was developed initially $\left.{ }^{14}\right)$ is quite general and the results are used to study this particular system. ${ }^{15)}$

The rate of progress of the reaction front within each grain is described as follows:

$$
\frac{\partial \xi_{\mathrm{G}}}{\partial \tau}=-\lambda_{1} \omega \gamma_{1} C^{*}
$$

where: $\left(D_{i} \cdot t\right) / R_{0}^{2}$ : dimensionless time, $t$ is the real time and $\gamma_{1}=\left(C_{\mathrm{o}} / \rho_{\mathrm{s}}\right)$ : ratio of molar gas concentration to molar density of solid reactant.

The initial and boundary conditions are:

$$
\begin{array}{r}
\xi_{\mathrm{G}}(\eta, \tau=0)=1 \ldots \ldots \ldots \\
C^{*}(\eta, \tau=0)=0 \ldots \ldots \ldots \\
\left.\frac{\partial C^{*}}{\partial \eta}\right|_{\eta=0}=0 \ldots \ldots \ldots . . . \\
\left.\frac{\partial C^{*}}{\partial \eta}\right|_{\eta=1}=\lambda_{2}\left(1-\left.C^{*}\right|_{\eta=1}\right)
\end{array}
$$

where, $\lambda_{2}=\left(h R_{\mathrm{o}} / D_{\mathrm{i}}\right)$ : dimensionless group and $h$ is the convective mass transfer coefficient.

The local extent $\alpha(\eta, \xi)$ and total extent $\varepsilon(\tau)$ of reaction are given by Eqs. (7) and (8), respectively:

$$
\begin{gathered}
\alpha(\eta, \tau)=1-\xi_{\mathrm{G}}^{3} \ldots \ldots \\
\varepsilon(\tau)=\int_{0}^{\eta} \alpha(\eta, \tau) \eta^{2} \partial \eta
\end{gathered}
$$

Equations (1) to (8) describe the general behavior of the system. The formulation presented thus far has the assumption of isothermal conditions. However, as it is known that heat can be generated or absorbed as a result of the chemical transformation, the temperature of the pellet will then be different from the gaseous reactant flowing past the pellet. This model was tested by generating asymptotic solutions for the limiting cases:

a) Chemical Reaction Control

$$
\xi_{\mathrm{G}}=1-\lambda_{1} \gamma_{1} \omega \tau=1-\tau_{\mathrm{c}} .
$$

where $\tau_{\mathrm{c}}=\lambda_{1} \gamma_{1} \omega \tau$ : dimensionless time when the chemical reaction at the interface is the rate controlling step. The extent of reaction in this case is given by

$$
\varepsilon(\tau)=\alpha(\tau)=1-\xi_{\mathrm{G}}^{3}=1-\left(1-\tau_{\mathrm{c}}\right)^{3}
$$


thus, $\varepsilon\left(\tau_{\mathrm{c}}=1\right)=1.0$.

b) Intraparticle Diffusion Control

$$
2 \Psi(\tau)^{3}-3 \Psi(\tau)^{2}+1=6 \kappa \tau=\tau_{\mathrm{D}}
$$

where $\Psi(\tau)=R_{\mathrm{I}} / R_{\mathrm{o}}$ : dimensionless radius of the diffusion interfaces, $K=\gamma_{1} /\left(1-\varepsilon_{\mathrm{o}}\right)$ and: $\tau_{\mathrm{D}}=6 K \tau$ : dimensionless time. The total extent of reaction is given by:

$$
\varepsilon(\tau)=1-\Psi^{3}
$$

thus, $\varepsilon\left(\Psi=0, \tau_{\mathrm{D}}=1\right)=1.0$.

c) Gas-Film Mass-transfer Control

$$
\varepsilon(\tau)=\tau_{\mathrm{G}}
$$

where $\tau_{\mathrm{G}}$ : dimensionless time is given by

$$
\tau_{\mathrm{G}}=\frac{3 \lambda_{2} \gamma_{1} \tau}{\left(1-\varepsilon_{\mathrm{o}}\right)}
$$

thus, $\varepsilon\left(\tau_{\mathrm{G}}=1\right)=1.0$.

The model was tested by studying the effects of the various dimensionless groups on the behavior of the system. Solutions to the general equation which describes the system are tested against the asymptotic solution for the limiting cases (rate controlling steps). The model is tested by first generating a solution using values of the dimensionless groups which produce so called mixed control (in the sense that it is neither diffusion nor chemical control). One dimensionless group was then varied (increased then decreased) while the others were kept constant and the tendency of the model to change towards one or the other of the asymptotes was observed. The numerical technique used to solve Eqs. (1) to (8) includes the Tridiagonal Algorithm, Runge-Kutta and Simpson-Richardson numerical methods. It should be pointed out that the dimensionless times chosen as independent variables $\left(\tau_{\mathrm{c}}, \tau_{\mathrm{D}}\right.$ and $\left.\tau_{\mathrm{G}}\right)$ provide a convenient representation of the behavior of the system.

\section{Experimental System}

The iron oxide pellets used in this research were commercially type pellets produced by Sidor Steelmaking Plant. Iron oxide pellets of two different sizes were used: type A pellet with mean diameter $1.07 \mathrm{~cm}$. and type B pellet with mean diameter $1.24 \mathrm{~cm}$. Typical analyses of these pellets are shown in Table 1. Pure hydrogen, pure carbon monoxide and Midrex gas mixtures were used as gaseous reductants. Midrex gas composition is: $\mathrm{H}_{2}: 55.7 \%$, CO: $34.0 \%$, $\mathrm{CO}_{2}: 6.3 \%$ and $\mathrm{CH}_{4}: 4.0 \%$. Gas flow rate of $2 \mathrm{~L} / \mathrm{min}$ was used in all the reduction tests so that external mass transfer did not constitute a rate limiting step. The experimental arrangement used for the reduction tests employed the conventional weight-loss method described elsewhere. ${ }^{15,16)}$

Table 2 shows the composition and flow rate of gas mixtures used in the reduction experiments. The pellets were characterized using atomic absorption, optical and electronic microscopes techniques. The physical properties of the pellets such as porosity and apparent density were measured using the ASTM standard methods.
Table 1. Characteristics of iron oxide fired-pellets.

\begin{tabular}{|c|c|c|c|}
\hline Mixtures & 1 & 2 & 3 \\
\hline $\mathrm{H}_{2}(\%)$ & 100 & 0 & 55.7 \\
\hline $\mathrm{CO}(\%)$ & 0 & 100 & 34.0 \\
\hline $\mathrm{CH}_{4}(\%)$ & 0 & 0 & 4.0 \\
\hline $\mathrm{CO}_{2}(\%)$ & 0 & 0 & 6.3 \\
\hline Flow(1/min) & 2.0 & 2.0 & 2.0 \\
\hline Temperature ${ }^{\circ} \mathrm{C}$ & 850 & 850 & 850 \\
\hline
\end{tabular}

\begin{tabular}{cc}
\hline Property & Quantity \\
\hline Size $(\mathrm{mm})$ & $9.5<\phi<12.7$ \\
Porosity & .22 \\
True density $\left(\mathrm{g} / \mathrm{cm}^{3}\right)$ & 4.7 \\
$\mathrm{Fe}(\%)$ & 67.64 \\
$\mathrm{FeO}(\%)$ & 0.58 \\
$\mathrm{SiO} \mathrm{O}_{2}(\%)$ & 1.28 \\
$\mathrm{CaO}(\%)$ & 1.00 \\
$\mathrm{Al}_{2} \mathrm{O}_{3}(\%)$ & 0.64 \\
$\left.\mathrm{MgO}^{2} \%\right)$ & 0.36 \\
$\mathrm{C}(\%)$ & 0.01 \\
$\mathrm{~S}(\mathrm{ppm})$ & 5.00 \\
\hline
\end{tabular}

Table 2. Composition of gas mixtures, gas flow rate and Temperature used in the reduction experiments.

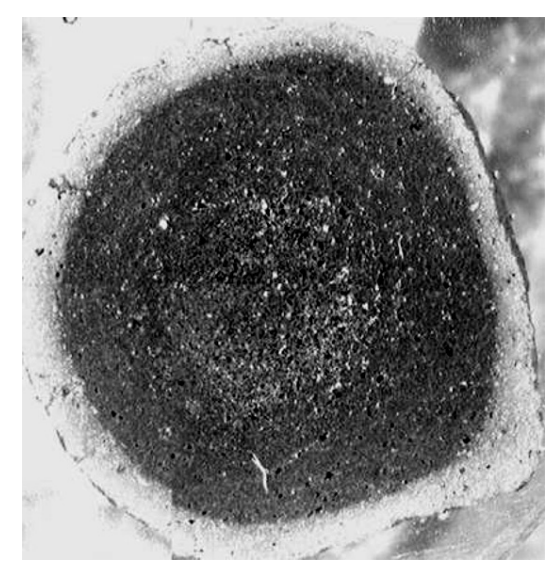

Fig. 1. Photo of partially reduced iron oxide pellet using Midrex gas mixture at $850^{\circ} \mathrm{C}$ after 10 min reaction.

\section{Results and Discussion}

The analysis of the experimental results confirms the applicability of the "grain model" to the reduction of iron oxide pellets. The macroscopic examination of a cross section of partially reduced pellet shows the topochemical behavior. Figure 1 shows a cross section of the partially reduced pellet using Midrex gas mixture, where a diffuse iron/wustite interface is observed. At higher magnification the microstructure of the individual grains which make up the pellet show a sharp topochemical iron/wustite interface as observed in Fig. 2. This type of behavior on the reduced iron oxides has been reported previously by several authors. ${ }^{17)}$ 


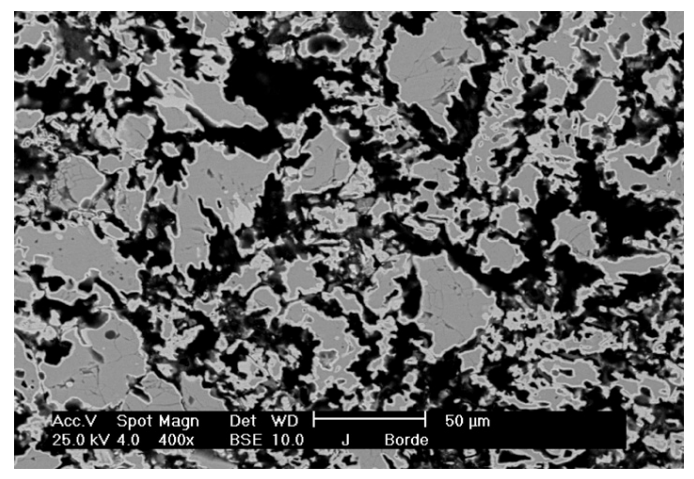

Fig. 2. Photomicrograph of partially reduced iron oxide pellet at $850^{\circ} \mathrm{C}$ for $10 \mathrm{~min}$ using Midrex gas.

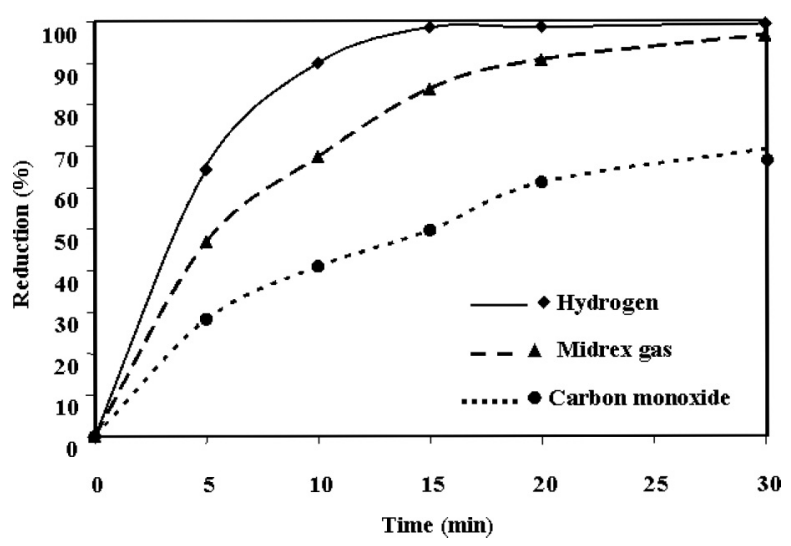

Fig. 3. Reduction of hematite pellets with $\mathrm{H}_{2}, \mathrm{CO}$ and Midrex gas at $850^{\circ} \mathrm{C}$ and $2 \mathrm{~L} / \mathrm{min}$ total gas flow.

Figure 3 shows typical reduction curves obtained for the reduction of type A hematite pellets using $\mathrm{H}_{2}$, Midrex gas and $\mathrm{CO}$. These experiments were carried out at $850^{\circ} \mathrm{C}$ and $2 \mathrm{~L} / \mathrm{min}$ total gas flow rate. As it has been reported in previous investigations, ${ }^{1,2)}$ the fastest reaction occurred when using $\mathrm{H}_{2}$ and the slowest rate is observed when using $\mathrm{CO}$ and the reduction with Midrex gas is intermediate. While under these conditions the reduction with $\mathrm{H}_{2}$ took about $15 \mathrm{~min}$ to go to completion, the reduction with $\mathrm{CO}$ required more than $30 \mathrm{~min}$. Figure 4 shows the comparison between the experimental results and the theoretical predictions (single dot and line) for the iron oxide reduction with $\mathrm{H}_{2}$. Despite the complexity of the system and the assumptions made, the mathematical model seems to provide a quite good fit to the experimental data for this system. A similar behavior is observed in the reduction of type $\mathrm{B}$ iron oxide pellets with $\mathrm{H}_{2}$.

Table 3 shows the theoretical data given by the mathematical model for the reduction of iron oxide type A pellets using $\mathrm{H}_{2}$. These data indicate some interesting features of the system. The relative values obtained for $\tau_{\mathrm{c}}, \tau_{\mathrm{D}}$ and $\tau_{\mathrm{G}}$ according to Eqs. (10), (11) and (13), respectively, indicate that during the first $5 \mathrm{~min}$ or $60 \%$ reduction, the rate controlling mechanism is a mixed controlled (chemical reaction and intraparticle diffusion) type, while intraparticle diffusion becomes more important after that, until the end of the reduction process. The values obtained for $\tau_{\mathrm{G}}$ indicate that, under the experimental flow conditions used, gas-film resistance to flow is negligible throughout the reduction process. A similar behavior is observed in the reduction of

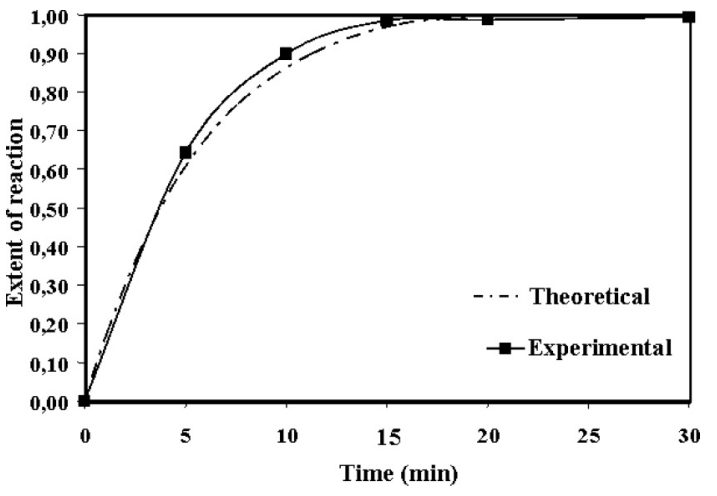

Fig. 4. Comparison between experimental and theoretical data for reduction of an iron oxide pellet type $\mathrm{A}$ with $\mathrm{H}_{2}$ at $850^{\circ} \mathrm{C}$.

Table 3. Theoretical data given by the model for the reduction of type $\mathrm{A}$ iron oxide pellet with $\mathrm{H}_{2}$ at $850^{\circ} \mathrm{C}$.

\begin{tabular}{ccccc}
\hline$\varepsilon$ & $\mathrm{t}(\mathrm{min})$ & $\tau_{\mathrm{c}}$ & $\tau_{\mathrm{D}}$ & $\tau_{\mathrm{G}}$ \\
\hline 0.06 & 0.36 & 0.07 & 0.03 & 0.91 \\
0.17 & 1.09 & 0.21 & 0.09 & 2.74 \\
0.37 & 2.54 & 0.48 & 0.20 & 6.38 \\
0.59 & 4.72 & 0.89 & 0.37 & 11.85 \\
0.77 & 7.63 & 1.45 & 0.60 & 19.14 \\
0.90 & 11.26 & 2.13 & 0.88 & 28.26 \\
0.98 & 15.62 & 2.96 & 1.23 & 39.20 \\
1.00 & 20.70 & 3.92 & 1.62 & 51.96 \\
\hline
\end{tabular}

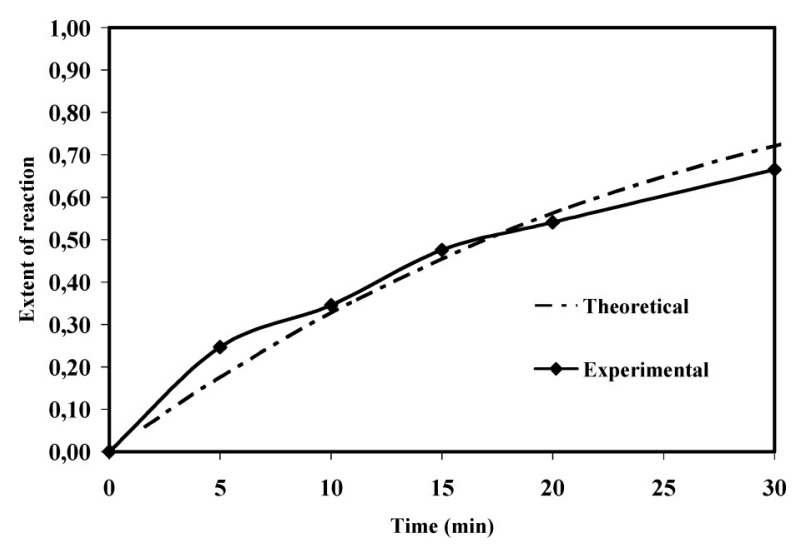

Fig. 5. Comparison between experimental and theoretical data for reduction of an iron oxide pellet type $\mathrm{B}$ with $\mathrm{CO}$ at $850^{\circ} \mathrm{C}$.

type $\mathrm{B}$ iron oxide pellets with $\mathrm{H}_{2}$.

Figure 5 shows the comparison between the experimental and theoretical data obtained for the reduction of iron oxide type A pellets using CO. This graph indicates that the curve fitting is not as well in comparison with that obtained for the reduction experiments using $\mathrm{H}_{2}$. This behavior may be due to different factors occurring in the reduction process of $\mathrm{FeO}$ with $\mathrm{CO}$. Edstrom ${ }^{18)}$ proposed a reduction process based on solid-state diffusion of ferrous ions. The precipitation of carbon on the surface of the grains due to the Bouduard reaction was studied by Towhidi et al. ${ }^{3)}$ These factors are still not very well understood. Table 4 shows the theoretical data given by the model for the reduction of iron oxide pellet using $\mathrm{CO}$. The relative values for $\tau_{\mathrm{c}}, \tau_{\mathrm{D}}$ and $\tau_{\mathrm{G}}$ indicates that the rate controlling mechanism is a mixed 
Table 4. Theoretical data given by the model for the reduction of type A pellets with $\mathrm{CO}$ at $850^{\circ} \mathrm{C}$.

\begin{tabular}{ccccc}
\hline$\varepsilon$ & $\mathrm{t}(\min )$ & $\tau_{\mathrm{c}}$ & $\tau_{\mathrm{D}}$ & $\tau_{\mathrm{G}}$ \\
\hline 0.05 & 1.52 & 0.05 & 0.03 & 0.81 \\
0.14 & 4.56 & 0.15 & 0.08 & 2.42 \\
0.31 & 10.64 & 0.35 & 0.20 & 5.65 \\
0.52 & 19.75 & 0.64 & 0.37 & 10.50 \\
0.72 & 31.91 & 1.04 & 0.59 & 16.96 \\
0.87 & 47.10 & 1.53 & 0.87 & 25.04 \\
0.96 & 65.34 & 2.12 & 1.21 & 34.73 \\
1.00 & 86.61 & 2.81 & 1.60 & 46.04 \\
\hline
\end{tabular}

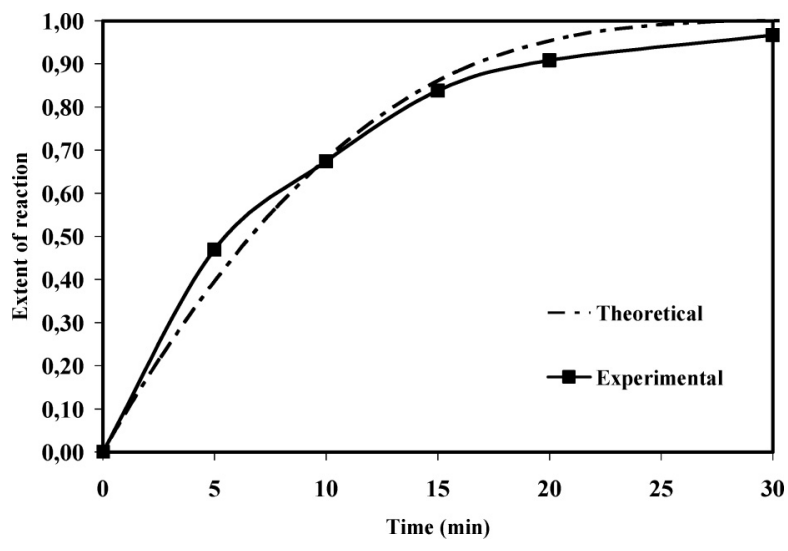

Fig. 6. Comparison between experimental and theoretical data for reduction of iron oxide pellet type A with Midrex gas at $850^{\circ} \mathrm{C}$.

controlled type, where diffusion and chemical rates are competing during the first $20 \mathrm{~min}$ of the reduction process and then intraparticle diffusion becomes the rate controlling step up to the end of the reduction process. The gas-film resistance to gas flow is negligible. A similar behavior is observed in the reduction of type B pellets.

Figure 6 shows the comparison between the experimental and theoretical data obtained for the reduction of iron oxide type A pellets using Midrex gas. This graph indicates that the fitting is much better than that obtained for the reduction with $\mathrm{CO}$ but not as well as the one obtained for the reduction with $\mathrm{H}_{2}$. Table 5 shows the theoretical data given by the model for the reduction of iron oxide type A pellet using Midrex gas. The relative values for $\tau_{\mathrm{c}}, \tau_{\mathrm{D}}$ and $\tau_{\mathrm{G}}$ indicates that the rate controlling mechanism is a mixed controlled type throughout the reduction process, while gasfilm resistance to gas flow is negligible. Moon et al. ${ }^{5)}$ proposed a mixed controlled mechanism for the reduction of hematite compacts (cylinders) under similar conditions to the present work. Their experimental results are closed to the results obtained in this work. The comparison of theoretical data given by applying the proposed model to Moon's experimental results showed a similar behavior to the reduction of iron oxide pellets using $\mathrm{H}_{2}, \mathrm{CO}$ and Midrex gas obtained in this work. The particle diameter of Moon's compacts was used as fitting parameter. The difference between experimental and theoretical data observed in the reduction with Midrex gas (Fig. 6) may be due to the complexity of the reaction mechanism which is still not well known, like the effect of the precipitation of carbon on the surface of the grains and other unknown factors related to
Table 5. Theoretical data given by the model for the reduction of type A pellets with Midrex gas at $850^{\circ} \mathrm{C}$.

\begin{tabular}{ccccc}
\hline$\varepsilon$ & $\mathrm{t}(\mathrm{min})$ & $\tau_{\mathrm{c}}$ & $\tau_{\mathrm{D}}$ & $\tau_{\mathrm{G}}$ \\
\hline 0.03 & 0.37 & 0.03 & 0.03 & 0.85 \\
0.10 & 1.11 & 0.08 & 0.09 & 2.56 \\
0.22 & 2.59 & 0.18 & 0.20 & 5.98 \\
0.38 & 4.81 & 0.33 & 0.37 & 11.10 \\
0.57 & 7.78 & 0.54 & 0.60 & 17.93 \\
0.74 & 11.48 & 0.79 & 0.88 & 26.47 \\
0.88 & 15.92 & 1.10 & 1.22 & 36.72 \\
0.97 & 21.11 & 1.46 & 1.62 & 48.67 \\
1.00 & 27.03 & 1.87 & 2.08 & 62.33 \\
\hline
\end{tabular}

the interaction between $\mathrm{CO}$ and the iron oxide. A similar behavior was observed for the reduction of iron oxide with CO (Fig. 5). The theoretical data given in Tables 3, 4 and 5 on the different $\tau$ 's values are given in conjunction with the real time in minutes (second column) elapsed from the starting of the reduction reaction.

By comparison between data given in Tables 3, 4 and 5, for the reduction with $\mathrm{H}_{2}, \mathrm{CO}$ and Midrex gas, respectively, the effect of gas composition on the rate controlling step is observed. As the CO content increases the reduction tends toward the chemical controlled process, where $\tau_{\mathrm{c}}$ is decreasing compared with those values obtained in the reduction with $\mathrm{H}_{2}$. However the overall behavior becomes a mixed controlled process.

\section{Conclusions}

The conclusions deducted from the present study on the reduction of iron oxide pellets with $\mathrm{H}_{2}$ and $\mathrm{CO}$ mixtures may be summarized as follows:

The kinetic model formulated to describe the reduction process has been shown to be successful and offers considerable promise in the study and better understanding of the direct reduction process.

The reduction of iron oxide pellets using $\mathrm{H}_{2}$ under the conditions studied in the present work is a mixed controlled type system, where chemical reaction and internal gas diffusion are competing processes during the first $5 \mathrm{~min}(60 \%$ reduction) of the process while internal gas diffusion becomes the rate controlling step during the last stages of the reduction process.

The reduction of iron oxide pellets using Midrex gas under the conditions studied in the present work is a mixed controlled system throughout the whole reduction process.

The reduction of iron oxide pellets using $\mathrm{CO}$ under the conditions studied in the present work is a mixed controlled type system during the first $20 \mathrm{~min}$ ( $50 \%$ reduction) of the process while internal gas diffusion becomes the rate controlling step during the last stages of the reduction process.

\section{REFERENCES}

1) A. A. El-Geassy, K. A. Shehata and S. Y. Ezz: Trans. Iron Steel Inst. Jpn., 17 (1977), 629.

2) L. A. Hass, J. C. Nigro and R. K. Zahl: Rep. Invest. U.S. Bur. Mines, 8997 (1985), 14.

3) N. Towhidi and J. Szekely: Metall. Mater. Trans. B, 14B (1983), 359.

4) H. W. Kang, W. S. Chung, T. Murayama and Y. Ono: ISIJ Int., 38 (1988), 1304. 
5) M. II-Joon, R. Chan-Hee and M. Dong-Joon: Steel Res., 69 (1998), 302.

6) A. Zhou, K. Suzuki, V. Sahajwalla and J. M. Cadogan: Scand. J. Metall., 28 (1999), 65.

7) R. A. D. Rodriguez and A. N. Conejo and A. N. Bedolla: Iron Steelmaker, 30 (2003), 25.

8) H. Y. Lin, Y. W. Chen and C. Li: Thermochim. Acta, 400 (2003), 61.

9) H. Ono-Nakazato, T. Yonezawa and T. Usui: ISIJ Int., 43 (2003), 1502.

10) J. Szekely and J. W. Evans: Chem. Eng. Sci., 25 (1970), 1091.

11) J. Szekely and J. W. Evans: Metall. Trans. B, 2A (1971), 1691.
12) J. Szekely and J. W. Evans: Chem. Eng. Sci., 26 (1971), 1901.

13) E. T. Turkdogan: Physical Chemistry of High Temperature Technology, Academic Press, New York, (1980), 229.

14) M. Manrique: M. Sc. Thesis, Colorado School of Mines, (1973).

15) A. Bonalde: Bs. Thesis, Universidad Simon Bolivar, (2004).

16) R. H. Spitzer, F. S. Manning and W. O. Philbrook: Trans. Metall. Soc. AIME, 236 (1966), 726.

17) J. J. Yang and W.-K. Lu: Proc. of the 44th Ironmaking Conf., Vol. 44, ISS-AIME, Warrendale, PA, (1985), 111.

18) J. O. Edstrom: ISI Journal, 175 (1953), 289. 